\title{
Steadfast is the rock: Primary health care Māori nurse leaders discuss tensions, resistance, and their contributions to prioritise communities and whānau during COVID-19
}

Josephine Davis ${ }^{1,3}$, MN, NP, Co-Leader National Nurse Practitioner \& Enrolled Nurse Workforce Programme, School of Nursing; Ngāpuhi

Coral Wiapo ${ }^{2}$, PGDip, RN, Regional Coordinator, National Nurse Practitioner \& Enrolled Nurse Workforce Programme; Ngāti Whatua

Hemaima Rehana-Tait ${ }^{2}$, PGDip, RN, Nurse Director; Ngāti Hine, Ngāti Kere, Ngāti Pihere and Ngāi Tahu

Terryann C. Clark ${ }^{1,2}$, PhD, Associate Professor, School of Nursing; Ngāpuhi

Sue Adams ${ }^{1}, \mathrm{PhD}, \mathrm{RN}$, Senior Lecturer/Co-Leader National Nurse Practitioner \& Enrolled Nurse Workforce Programme, School of Nursing; Tauiwi - Western European Indigenous Ally

${ }^{1}$ University of Auckland, Auckland, Aotearoa New Zealand ${ }^{2}$ Mahitahi Hauora PHE, Tai Tokerau/Northland, Aotearoa New Zealand

${ }^{3}$ Corresponding Authors: josephine.davis@auckland.ac.nz; s.adams@auckland.ac.nz

\section{Citation}

Davis, J., Wiapo, C., Rehana-Tait, H., Clark, T. C., \& Adams, S. (2021). Steadfast is the rock: Primary health care Māori nurse leaders discuss tensions, resistance, and their contributions to prioritise communities and whānau during COVID-19. Nursing Praxis in Aotearoa New Zealand, 37(3), 84-93. https://doi.org.10.36951/27034542.2021.038

\begin{abstract}
Historical experience from previous pandemics, together with knowledge of significant and perpetuating health inequities, led to predictions that Māori and Pacific peoples would experience greater morbidity and be hardest hit economically. Steadfast is the rock describes the mahi (work and actions) of three Māori nurse leaders through the first COVID-19 lockdown in Aotearoa New Zealand in 2020. Through kōrero (discussion and dialogue), this article draws on their experiences of working in a large mainstream primary health entity working across the Northland region of Aotearoa as they navigated their way within and across health sector providers and organisations to protect the health and wellbeing of whānau (families). They used their knowledge of mātauranga Māori (Māori knowledge and tradition), to ensure Māori whānau were prioritised in the pandemic response in the region. They faced adversity and resistance in a fragmented system where competition and power interfered with collaborative practices. Throughout, they remained courageous and resilient, holding true to mātauranga Māori as nurses and Māori wāhine (women) to promote equity. Yet much of their work went unnoticed and unacknowledged. Māori nurse leaders hold a necessary role in providing an equityfocused response across mainstream and Māori health providers, through their abilities to maintain relationships, find mutually agreeable strategies, and work collaboratively across the health sector.
\end{abstract}

Keywords / Ngā kupu matua: COVID-19; dialogue / whakawhiti kōrero; Indigenous / Iwi taketake; inequities / ngā korenga e ōrite; Māori; nursing leadership / kaihautū tapuhi; pandemic / mate urutā; primary health care / taurimatanga hauora tuatahi

For Māori terms, please see the Nursing Praxis Te Reo Glossary

\section{Te Reo Māori translation}

He toka tū moana: Ka whakawhiti kōrero ngā kaihautū tapuhi Māori taurima hauora tuatahi mō te āmimai, te ātete, me ā rātou mahi arotahi ki ngā hapori me ngā whānau i te wā o COVID-19

\section{Ngā ariā matua}

Nā ngā wheako o ngā urutā o tau kē, nā te mātauranga hoki mō ngā korenga e ōrite o ngā āhuatanga hauora nui, e haere tonu nei kāore he mutunga, kua ara ake ngā matapae tērā pea ka kaha ake te mate rawa me te pā nui hoki o ngā raru hauora ki ngā iwi Māori me ngā iwi o Te Moana-nui-a-Kiwa. Ko tā tēnei puka Steadfast is the rock he whakaahua i ngā mahi me ngā kōkiri a ètahi kaihautū tapuhi Māori i 
roto i te katinga COVID-19 tuatahi i Aotearoa i te tau 2020. Nā te kōrero, ka kitea ngā wheako o ēnei tapuhi i a rātou e mahi ana mō tētahi hinonga hauora tuatahi rahi puta noa i te Tai Tokerau i Aotearoa, i a rātou e kōpikopiko nei i roto i te rāngai hauora ki te tiaki i te hauora me te toiora o ō reira whānau. I tahuri rātou ki te mātauranga Māori, kia tōia ngā urupare ki te urutā i te rohe ki runga i ngā whānau Māori. I kitea e ratou te uaua me te ātete i tētahi pūnaha kōhao rau, ko ōna tohu ko te whakataetae me te aruaru hē i te mana. I te roanga atu o ngā marama i tū māia tonu rātou, i tū pakari, me te piripono anō ki ngā kaupapa taketake o te tapuhi tūturu, hei wāhine Māori hoki, kia whiwhi painga te katoa. Ahakoa, kāore i āta kitea, kāore i mihia te nuinga o ā rātou mahi. He tūranga taketake tō te kaihautū tapuhi Māori, kia whiwhi painga te katoa i roto i ngā kaituku hauora auraki, me ngā kaituku Māori, nā tō rātou kaha ki te whakapakari hononga, ki te kimi rautaki haratau ki ngā taha katoa, ki te pāhekoheko hoki puta noa i te rāngai hauora katoa.

\section{Introduction}

\section{He toka tū moana he ākinga nā ngā tai}

\section{Steadfast is the rock that scorns the lashing tides}

The COVID-19 pandemic across the globe has disproportionately affected Indigenous Peoples, People of Colour, and poor communities (Crooks et al., 2021; Evans, 2020). At the beginning of the pandemic in Aotearoa New Zealand, in late February 2020, it was anticipated that Māori and Pacific peoples and communities would experience greater morbidity and long-term consequences from COVID19 (Ministry of Health, 2020a). The initial Māori COVID-19 response plan (Ministry of Health, 2020b) was released on $16^{\text {th }}$ April 2020, more than six weeks after the first case in Aotearoa. The plan stated:

It is evident from previous pandemic responses that the business-as-usual model previously used preferentially benefited nonMāori and failed to protect whānau, hapū, iwi and Mãori communities from the worst outcomes. It is critical that the specific needs of Mãori, particularly equity and active protection, are integral to the health and disability response to COVID-19 (Ministry of Health, 2020b, p.5).

However, well before this plan and any governmental restrictions were implemented, Māori leaders had identified the vulnerability of their communities to COVID-19 and were beginning to take protective measures (Dawes et al., 2021). Socio-economic deprivation, compromised living conditions, existing poorer health status and age, and poor health literacy all increase risk for Māori for hospitalisation and death from COVID-19 (Dawes et al., 2021; Steyn et al., 2021). Across the health system, Māori are more likely to have negative experiences, including encountering racism, discrimination, and marginalisation at an interpersonal level as well as through institutional structures and processes (Cormack et al., 2018; Wilson et al., 2021).

While there has been criticism levelled nationally that the Government has failed to adequately involve Māori to co-design the COVID-19 response (Dawes et al., 2021), the pandemic has seen Māori leadership proactively respond to protect their communities. Reflections and research have identified that many effective and culturally appropriate strategies were locally driven by iwi, hapū, and Māori hauora (health and wellbeing) leaders in a way never seen before (Dawes et al., 2021; McMeeking et al., 2020). A Kaupapa Māori study with 23 kaumātua (Māori elders) on their experiences of COVID-19, found that despite kaumātua feeling excluded from Government decisions, iwi and whānau-initiated responses promoted some sense of rangatiratanga (selfdetermination): "Māori doing it for themselves" (Dawes et al., 2021, p. 532).

Nurses are often exposed to difficult and stressful working environments, which has been heightened by COVID-19. Delgado et al., (2017) describe how the very nature of nursing requires that nurses are agile in their responses and that they maintain resilience to deliver effective and quality care. However, for many Māori nurses they experience both the complexities of nursing and what can also be the additional challenges of being Māori (Hunter \& Cook, 2020). In Aotearoa, Māori nurses are instrumental in leadership roles in both their community as well as workplace settings. For many of these Māori nurse leaders, navigating between the world views of the mainstream western Eurocentric system and te ao Māori is their reality. Both these world views present challenges to Māori nurses to deliver healthcare (Ruru et al., 2017). However, it is the traditional values of Māori leadership such as tikanga (cultural 
protocols), manaakitanga (respect, reciprocity), and whānaungatanga (connectedness), which may have the most positive influence (Haar et al., 2017).

This article presents the perspectives of Māori nurse leaders (as co-authors) from a primary health entity (PHE) covering the large geographical area of Tai Tokerau (Northland). The PHE has a similar function to primary health organisations (PHOs) which are publicly funded through local district health boards (DHBs) to ensure essential primary health care services are delivered to people enrolled with the PHO. The majority of services are delivered through mainstream general practice and the PHO model has been strongly critiqued as failing to meet te Tiriti obligations resulting in ongoing significant health inequities (Kidd, et al., 2022). The nurse leaders found themselves in the thick of the pandemic response as they navigated their way between systems, processes, organisations, and iwi to ensure Māori whānau received the information, support, and services they required.

Approximately 70,000 (35.8\%) people living in Tai Tokerau identify as Māori and more than half experience high levels of socio-economic deprivation (quintile five) (Ministry of Health, 2021). Rurality; poor infrastructure, including roading and transport; and reduced access to healthcare, food, and other community resources, add to the challenges of maintaining hauora. To compound the start of the pandemic in 2020, Tai Tokerau was experiencing a severe drought with water being transported into some communities for drinking, while Government information was driving the need for handwashing. Early on, a positive case was identified in one of the local communities, signaling that COVID-19 had well and truly arrived. The Māori nurse leaders' mahi through the pandemic has been underpinned by knowing the vulnerability of whānau and the determination to deliver equitable outcomes for Māori.

The title and whakataukī, "steadfast is the rock," intends to frame the introduction. It refers to one who is steadfast and strong in their culture, beliefs or position against all opposition. It is used in this paper to contextualise the many demands, responsibilities, and pressures experienced by Māori nurse leaders as they negotiate their roles as nurses, employees in mainstream services, wāhine Māori, mothers, grandmothers, hapū and iwi members.

\section{Approach}

The purpose of this piece is to describe the leadership activities and experiences of a group of Māori nurse leaders employed in a mainstream PHE during the first COVID-19 lockdown in 2020. Conversations with the five authors were held during August and September 2021 by face-to-face and by Zoom. Through kōrero (discussions) we captured the stories, insights, frustrations, and solutions of three of the authors in their role as Māori nurse leaders (CW, HT, and JD). The conversations were informal and fluid. Notes were taken, and the kōrero recorded and transcribed. Notes and transcripts were returned for all of us to review and we worked collaboratively to identify themes arising to write the article.

We used a narrative approach to record the Māori nurse leaders' stories to begin to collectively make sense of their experiences. We drew on the work of Caine et al. (2021) who undertook an inquiry into their own lives, as authors, reciting their stories to unpack the dominant narratives of the pandemic, describing how these dominant narratives "create[d] multiple complexities as they collide[d] with our everyday lives as embodied and situated people, as nurses, educators, and women" (Caine et al., 2021, p. 2). Additionally, we drew on Kaupapa Kōrero, an approach that embraces Māori customary practices through the oral tradition of kōrero (a conversation or discussion) (Ware et al., 2018). Kaupapa Kōrero brings together the key principles of Māori research, privileging Māori customary practice and understanding to create shared knowledge.

Both Josephine Davis (Ngāpuhi) and Hemaima Tait (Ngāti Hine, Ngāti Kere, Ngāti Pihere and Ngāi Tahu) were nurse directors of the PHE; and Coral Wiapo (Ngāti Whātua-Kaipara) was the locality network lead. Terryann Clark is Māori (Ngāpuhi) and works part-time at the PHE coordinating child and youth health promotion and part-time as an Associate Professor, School of Nursing at the University of Auckland. Sue Adams is tauiwi (non-Māori) and working closely with the PHE on a nursing workforce programme to increase the number of Māori nurse practitioners and Māori enrolled nurses working within the community. The Māori nurse leaders were part of the Executive Leadership Team (ELT) at the PHE and utilised their roles to influence practice and advocate for an equity perspective. 


\section{Ngā kōrero and arising themes}

\section{Stepping up to the task: COVID-19 reaches Te Tai Tokerau}

Ki te kotahi te kākaho. Ka whati; ki te kāpuia, e kore e whati

If a reed stands alone, it can be broken; if it is in a group, it cannot

I felt the fear. I knew there was a real risk to our Mâori community based on the knowledge of our history. As a nurse, I knew I was going out into what could be a risky situation. I felt anxiety and fear for myself and my extended family. But I felt the weight of being a Mãori nurse; that our Mãori community and especially our rural Mãori community was going to be hardest hit and that I was walking into something huge. [CW]

As the Level 4 lockdown became imminent (starting 25 March 2020), the Māori nurse leaders mobilised themselves and their teams into action. While the Public Health Unit (PHU) at the DHB were establishing an internal Incident Management Team (IMT) leading up to the level four lockdown, "primary care and Māori providers were crying out for local information and clinical guidance" [JD]. The PHE began organising its own response and internal team before becoming a part of the wider DHB IMT. JD, CW, and HT along with three other nurses (one Māori and two tauiwi) were a part of the internal PHE leadership team. JD described the interweaving of leadership and teamwork:

The six of us mostly worked from the office. We were fortunate that we all had strong working relationships prior, knew each other well, worked to each other's strengths, and flexed to fill gaps and need. All the nurses had a very strong focus on ensuring our communities were supported. Finding extra nursing staff; redeploying staff to work with providers who needed help; sourcing scrubs and PPE [personal protective equipment] for staff; addressing clinical concerns and other issues from staff and providers; developing and delivering a training for nurses and kaimahi [non-regulated health workers]; covering two 0800 [freephone] numbers; and preparing surge plans, if need overwhelmed general practice, were just some of the things we did.
There were many demands and frustrations from all sides to get the system up and running. People were afraid, the system was not prepared, and people were at risk. Māori nurse leadership in this space was to leverage their relationships, 'roll up their sleeves', and provide practical support, coordination, processes, and procedures in the call for action.

Leveraging our networks and relationships: Whānaungatanga in a time of COVID-19

\section{Ehara taku toa i te toa takatahi taku toa takitini taki mano e \\ Success is not the work of an individual but the work of many}

A central concept in te ao Māori is whānaungatanga, the process of engaging and reciprocating a sense of connectedness in relationships. Regular Zoom hui were held with key stakeholders and external staff to provide information, support, and to hear and be able to escalate their "on-the-ground concerns" [JD]. People were receiving their communications about COVID-19 from TV, radio, and mainstream and social media:

\section{We spent much time debunking erroneous media messages about what was or was not happening. In addition, the landscape changed frequently, and we were all learning. Communications were changing daily and sometimes several times within the day. You had to get judicious about the priority of the messaging as message fatigue was resulting in increased anxiety and frustration. Maintaining communication was key. [JD]}

Early in the pandemic, when providers were beginning to test for COVID-19, the Māori nursing leadership team were asked to support a Māori health provider in a rural area, which had just a few nursing staff and kaimahi. Because of connections with the local hapū, one of the Māori nurse leaders brokered the relationship with the provider to support the COVID-19 response in that community. JD highlighted the importance of prior relationships to enable a swift response:

"As a Mãori wahine [woman], she had the whakapapa [iwi connections] and relationships. She was seen to be a safe pair of hands who had the trust of the community and was able to break down the barriers and negotiate with them [the provider]." 
Despite some challenges, HT reflected that, "I never lost sight of my responsibility as a leader to continue to engage and maintain relationships." She was able to move fluidly between the PHE, the provider, and whānau.

Māori nurse leaders utilised their problem-solving skills, leveraged their relationships and their leadership to influence and ensure that COVID-19 testing sites and protocols were established for safe staffing and to create a better experience for whānau. When they saw something that was not working and instead putting people at risk, they developed alternatives and demanded these be changed. HT noted they were able to be influential due to their mana-enhancing practices:

\section{We walked into the space in an honouring and acknowledging way, to mobilise the resources with a collaborative frame. Our aim was that every person who came through a site was dealt with in the best possible way. Kaumàtua and Kuia [female elders] were looked after, we shaped our conversations so that people had understanding. They felt cared for and when they left, they felt informed.}

Across the region, the Māori nurse leaders were actively engaged in working with providers and iwi to develop projects to support Māori whānau. Their work included training and supporting kaimahi; project design, planning and evaluation and ensuring whānau were well connected to other community and health resources and services. Whanaungatanga was essential to the success of their work.

\section{Creating pandemic Tikanga protocols}

\section{Kia mau ki to Māoritanga \\ Hold fast to your Māori heritage}

One of the first requirements of the pandemic response was to 'stand up' (a termed coined during the pandemic to mean set up) COVID-19 testing stations. Considerable fear was present within the community from the outset of the pandemic. CW noted widespread distress:

The Māori health workforce were themselves fearful, as many were highly vulnerable to COVID-19 due to age, pre-existing health issues and risk of infection to their own whānau. The kaimahi became frontline workers, particularly at COVID-19 testing sites. Staff often faced considerable challenges when interacting with whänau who were stressed and scared, and [the staff] were, at times, being verbally abused.

To protect the staff, HT introduced tikanga protocols. At community-based assessment and testing stations for COVID-19 (known as CBACs), each site was initially blessed, and every morning began with a karakia to "ensure everyone who worked there went home safely and well" [HT]. A karakia is a prayer or incantation used to invoke spiritual guidance and protection and to promote goodwill amongst a group of people. HT reflected on the unifying effects of tikanga:

\section{Uniting with others made it easy to implement tikanga protocols. It also normalised these practices to shape and sustain the way we operated each day. It gave us a sense of togetherness and purpose.}

At the end of the day, a tikanga de-robing process (of PPE) and showers (where available) took place, so workers went home cleansed and well:

As a nursing professional at the end of the day I felt a sense of duty about sending everybody home well... We had a protocol for having a shower, changing our clothes and leaving behind our shoes. It made sense to me that the other protocol was for our wairua [spirituality]. We started the day with a karakia [prayer] and so we should end the day that way. From a nursing perspective and tikanga Mãori, wairua is so important. [HT]

CW, who helped with testing at this site, described how having "karakia and tikanga wrapped around us, really helped me as a Māori nurse to alleviate some of the fear and to feel safe and protected."

Back at the PHE office, karakia was held by Zoom every morning at 8.30 for all staff. This helped ensure staff "remained connected and informed in the fastpaced fast-moving nature of COVID information and strategies" [JD]. It also enabled those working from home to catch-up with those working in the communities. Staff working behind the scenes at the PHE, and often from home, found that hearing stories from the Māori nurse leaders about what was happening across the region, helped their "colleagues understand the reality, rather than receiving their knowledge from the media." Upholding tikanga that kept people safe, kept them informed and acknowledged the work of all people in the pandemic 
was vital for teams to remain safe physically, emotionally, and spiritually.

\section{Mistrust, agendas, and money: Conflicting worldviews}

He ora te whakapiri, he mate te whakatakariri

There is strength in unity, defeat in anger/division

The Māori nurse leaders emphasised the complexity of both the health system response and their positioning at various levels of the health sector, from local to regional and national. They described their involvement with many people across multiple organisations. These included the Ministry of Health, the DHB, and the DHB's public health unit, the PHE, iwi, Māori health providers, mainstream general practices, and community and whānau. Within these structures, the nurse leaders were also supporting the nursing workforce.

JD portrayed the complex interpretive mahi in their roles:

Many different agendas were circulating and there was constantly changing information and advice on a daily basis. People from the different organisations had different ideas as to what to do next and often these were conflicting. It felt like we were negotiating and advocating for one group; going to the next and setting the picture and reframing; then going back, interpreting, renegotiating and reframing, trying to find a way forward; and all the while ensuring we met the needs of whānau.

They identified how at times they felt 'caught in the middle' and continued to meet resistance to work as a collective. CW noted the power struggles that undermined the response:

We had to negotiate the politics, and often the tensions between and within the groups made this challenging. We met resistance from the $D H B$ and from general practice. It is innate for us as Māori to work together and collaborate. There was network resistance because while the Māori health providers needed help, they still wanted to maintain control of their role as provider, which made it a difficult space for us to negotiate within. It just seemed to us like what was the most straightforward and natural response was constantly being met with resistance from others.
Specifically, the Māori nurse leaders noted the tensions between mainstream/Western services and Māori health/Iwi providers. Particularly they highlighted the challenges for the PHE whose members were mainstream general practices as well as Iwi and Māori health providers. Within the PHE, JD described how they were "often justifying the Ministry of Health's rationale for equity [to mainstream providers] and providing for whānau Māori," highlighting the role of institutional racism and resistance when trying to divert resources from mainstream to Māori providers. CW described how mainstream practices appeared "suspicious" of the health system's funding mechanisms through the PHE and seemed to have "little understanding of the PHE's role in supporting and prioritising Māori communities and whānau." Overall, there was "little trust in the system."

A backdrop to the tensions noticed between mainstream and Māori health was that the context that the pandemic had perhaps exacerbated racism towards Māori in society, fuelled in part by the negative portrayal of Māori by the media. CW illustrated how local Māori were protecting their communities from people outside their area bringing in COVID-19:

\section{For example, Māori were taking ownership and protecting our communities. The media said that Māori were making roadblocks, but in fact Māori would describe them as checkpoints, where they were talking to people and informing them about keeping their communities safe. That finger-pointing and bringing Māori to the front in terms of not conforming and going rogue was how the media portrayed it.}

The nurse leaders talked about "patch protection" and the "powerplay" going on across the sector. For example, they recalled regular discussions at meetings where funding was hotly debated; how providers were losing income and who should fund the shortfall; how funding from non-delivery of contracts could be diverted to COVID-19 work; and how and by whom, decisions of COVID-19 funding, and expenditure were being made.

HT spoke of the work she had done in setting up a COVID-testing station for a Māori health provider who had been funded to do this but appeared not to have the capacity nor capability. She "played a very careful balancing act" to maintain the relationships 
between herself and the kaimahi, the manager of the provider, the PHE, and DHB. She noted her careful approach to navigating this situation:

I was very proactive and assertive in places where I could without upsetting the dynamics and blowing the whole operation, because the dynamics were too delicate and the situation was too risky to upset.

The Māori nurse leaders agreed there were occasions where they experienced "horizontal violence" as they were caught up in the politics with providers who did not share their understandings of mahitahi (working together). For instance, the PHE staff who were diverted into the community to assist at DHB testing sites were told they had to bring their own PPE. "You're not our staff, so we don't need to provide you with anything," they were told. Māori nurse leaders resorted to carrying extra PPE gear in their cars to ensure all PHE staff were safe. Such acts of exclusion and bullying could easily "suck the energy and compassion out of our work." However, it was their professional integrity and responsibility to their communities that helped them "keep it all together."

\section{Resilience, courage, and manaakitanga}

Whakapūpūtia mai ō mānuka kia kore ai e whati

\section{Cluster the branches of the manuka so they will not} break

Despite the challenges, tensions, and even a "level of violence" experienced, they continued in their work, guided by the principle of manaakitanga. Manaakitanga is a central Māori value that expresses respect for others, responsibility, and reciprocity; and ultimately the Māori nurse leaders were focused on protecting the health of communities, regardless of the burden placed on them as individuals:

I am not interested in praise. I'm just talking about let's get on with that work, let's get on with that work as professionally as possibly. I think from a nursing point of view, it takes courage as a Mãori nurse to stand up to that level of violence, and to have to repeatedly stick up for myself and the community... If it is the right thing to do then I just go and do it. [HT]

CW highlighted her sense of accountability during an incident where she was challenged by a Māori leader about the (lack of) work of the PHE during the pandemic, and, by inference, the nursing team:
I think I was stepping into that space as a wahine Màori and saying, "No, I'm not going to stand by and let you say what the organisation has and has not done." I think we were all courageous; and part of that is we feel accountable to our collective and our communities.

JD continued with the theme of courage:

I think that word courage is something that all
the Mãori nurse leaders during the pandemic
displayed. We were all leaving our homes and
families to care for everyone else's whänau.
We had to assertourselves with hierarchy that
we would not usually have to. I think we all
were constantly pulling out the 'courage card'
just to make things happen, to do what we
needed to do despite others thinking
differently.

For the Māori nurse leaders who were moving between sites across the region, the lockdown posed challenges to their wellbeing and safety. Travelling times were long (several hours in one direction), public toilets were all closed, and there was no food available on the road. CW depicted the many discomforts:

We stood in the rain, it was wet and windy, behind masks and at the required distance from the car to try and take details of whānau who had their window wound down just a little. There were no toilets, no food available. We were drenched and cold by the end of the day and had a long journey home.

The Māori nurse leaders epitomised resilience, courage, and commitment. They witnessed many examples of poor process, bullying, patch protection, and a lack of willingness to share resources. Despite these obstacles, Māori nurses advocated, negotiated, and facilitated changes to the system as expressions of manaakitanga.

\section{Whakaiti: Responding with tika, pono, and aroha}

Kāore te kumara e kōrero ana mo tōna ake reka

The kumara does not brag about its own sweetness

Tika, pono, and aroha (integrity, respect, and compassion) were values central to the work of the Māori nurse leaders. They described how they worked "quietly" to achieve the outcomes required necessary to promote the health and wellbeing of 
whānau in a way which maintained the respect and mana (prestige, honour) of Māori whānau. They discussed the concept of whakaiti, which HT described as being "inconspicuous and unnoticed as we go about our work." CW added how their "intangible actions were not visible, but what was seen was the data, the numbers, and not our work." Yet they believed that their work made a considerable difference. In the new PHE pandemic planning document there is no acknowledgement of the relational work of the Māori nurse leaders; of the tika, pono, and aroha they brought to their work.

JD's strategy was to "fit myself into the gaps" to ensure the knowledge and directives of the DHB Public Health Unit and the ELT of the PHE moved appropriately through to the providers and the community. She said, "there was a lot of quiet doing." They discussed how they used their "wisdom to ensure the safety of their team and the community," showing their compassion and care. HT likened this to the role that Māori wāhine fulfil as kaikaranga on a marae, where, in addition their role to call visitors onto the marae, they observe tikanga and ensure the mana of all is respected. Here, they too identified that the skills of problem-solving and critical thinking from their nursing background helped with their decisions and actions as leaders. As HT recounts:

When you do your work properly, we are really economical. We don't need much to look after ourselves, we are not looking for praise, we just want to see the job done well. And that was the prize to get to the end of the day without any incident and to manage our situation challenges with some level of professionalism to make sure that every person who came through that site was dealt with in the best possible way.

Having something to celebrate and some joy through these difficult times was important. HT describes:

One of our fondest moments of our workday was to come into the office at end of day, we had a handwritten dashboard, and every day we would count up the number of swabs and the work that was completed for the day, and that was our celebration.

2020 was the International Year of the Nurse and celebrated on 12 May. The nursing leadership team across the sector had planned a rolling schedule of opportunities that celebrated, showcased, and acknowledged the contribution and everyday mahi of the nurses. These opportunities were interrupted but it was important that the Māori nurse leaders demonstrated the respect and honour they felt for the nurses, despite the challenges of how to accomplish this acknowledgement. The team put together hampers and delivered them to every hauora (health) provider, mainstream and Māori, across Tai Tokerau:

One nurse rang on behalf of her team to talk about how they as nurses in a Mãori provider had supported their community with regular care, swabbing, education, and aroha, and how it wasn't even acknowledged on [International] Nurses' Day. I asked, "Did you get the hamper? You were all out and about and I left it at the front desk. We see your work, we know what you are doing for your communities." It's a small something to say 'thank you.' Several days later I got an email. They had got together as a team, had morning tea, and shared their hamper. It was an opportunity for them to connect, share, and kōrero. They said they had "gotten some space to breathe." [JD]

Additionally, HT put together a video of nurses from across the region to celebrate International Nurses' Day. She said, "It was a record of our fun that we also had. It gave us a little bit of joy."

TC reflected on the conversation:

Those were moments of joy when we were acknowledging each other. Politically we couldn't speak up about many things. It is good to hear you talking about all the things you were doing behind the scenes, "fighting the fight". But that whole whakaiti, not talking stuff up, not being acknowledged for what you were doing; so much of what you were doing was not seen. And it makes me sad to hear of all the challenges you faced, at times how you were treated, and the bad behaviour. But that happens when people are pushed and feeling anxious and blamed. How do we respect each other's contributions, so that we don't have to keep being courageous and pushing back?

So much of the Māori nurse leaders work was unseen by DHBs, the PHE, general practices, Māori health providers, and the general public. Using Māori values of tikanga, whānaungatanga, and manaakitanga were central to the success of protecting the health and wellbeing of their communities. 


\section{Implications and recommendations}

Tini whetu ki te rangi, he iti to pokeao ka ngaro

\section{A small cloud overhead will obscure the stars}

These findings from this kōrero provide valuable lessons in how Māori nurse leaders negotiated multiple spaces, places, and roles within their organisation to uphold the mana of whānau Māori and facilitate a more equitable system. There were times when Māori nurse leaders were fierce advocates, other times careful negotiators and strategic politicians, all while maintaining their relationships, responsibilities, and the sense of joy at making a difference. There are some important lessons here that future pandemic strategies need to consider.

First, pandemics can magnify inequity for Māori communities (Steyn et al., 2021; Wilson et al., 2012). Efforts to address inequities requires layers of Māori leadership at government, district health boards, primary health organisations, general practices and Māori health providers. Nursing leaders hold necessary roles in promoting equity and holding racism to account across the healthcare sector, when the sector is scrambling to respond from a systems, clinical, and coordination perspective (Jenkins et al., 2021; Kidd et al., 2020). The default emergency system response in the pandemic was not to meet the needs of whānau Māori or an equity focused response, despite the rhetoric. This lack of oversight also highlights the need for Māori nursing leadership within mainstream and Māori health services to ensure these tensions are addressed.

Second, Māori nurse leaders bring with them exceptional skills that combine problem-solving, critical reflective practice, experience, and mātauranga Māori, demonstrating too their sociopolitical awareness (Kidd et al., 2020). Māori nurse leaders showed how they "observe[d] and use[d] their wisdom to fill the gaps and spaces to provide a culturally safe environment". They have the ability to move through and across layers of organisation and bureaucracy and within whānau and communities in a non-threatening but determined manner. Whānaungatanga and the ability to maintain relationships, find mutually agreeable strategies, and remain compassionate are essential skills to promote equity.

Third is the concept of whakaiti, to quietly and solidly get on with the task, while upholding the responsibility of leadership for whānau wellbeing (Haar et al., 2019). Māori nurse leaders are held accountable from multiple levels: their employer, Māori health colleagues, whānau and communities. Much of this nursing work is unseen, stemming from a responsibility for collective wellbeing and working for the greater good, without exclaiming what they have done and what they have achieved. Māori nurse leaders also saw many examples of poor practice and institutional racism that threatened the wellbeing of whānau during the pandemic (Steyn et al., 2021).

Incidents left the nurse leaders personally vulnerable to bullying, exclusion, and burnout. Rather than engaging in patch-protection or attributing blame, nurse leaders nurtured relationships and collaborations to try and maintain momentum during the pandemic. The support of Māori nursing leader colleagues and Pākehā (white European)/tauiwi allies are necessary to enable this quiet determination to continue (Hunter, 2019). Maintaining Māori nursing leadership in this space requires a strong and unwavering focus on the "big picture' and good outcomes for whānau.

Finally, the healthcare sector responded in how it was designed - based on neoliberal, individual, and competitive contract-driven responses (Health \& Disability System Review, 2020). The fragmentation of the health system, competition, and power and control was evident through the conversations with the Māori nurse leaders. It is difficult to have genuinely collaborative pandemic responses when low trust contracting practices are maintained, with large mainstream health organisations facilitating and maintaining control over resources and funding. This stranglehold created resentment by privatelyowned general practices and Māori health providers with Māori nursing leaders often facing criticism from many services.

The COVID-19 pandemic has provided a uniquely stressful working environment for all health workers in Aotearoa New Zealand, pushing people, resources, and systems to the limit. We need to move towards a collective health system that facilitates collegiality and cooperation, creating trusting and respectful relationships with whānau to protect and promote their health and wellbeing. Māori nurse leaders are well positioned and well connected with their communities. This is not unique to the Māori nurse leaders in this primary healthcare entity and their stories will resonate across many other areas of 
Māori nursing leadership. Together, they have shown they are steadfast as a rock, resilient, and courageous. It is now time to acknowledge their work underpinned by mātauranga Māori and give support and mana to their leadership skills and roles. We welcome the health and disability system reforms with its renewed and genuine commitment to equity, and the necessity of valuing the contribution of Māori nursing leadership.

\section{References}

Caine, V., Steeves, P., Berendonk, C., Blix, B. H., \& Jean Clandinin, D. (2021). Narrative care: Unpacking pandemic paradoxes. Nursing inquiry. Adv online pub. https://doi.org/10.1111/nin.12462

Cormack, D., Stanley, J., \& Harris, R. (2018). Multiple forms of discrimination and relationships with health and wellbeing: Findings from national cross-sectional surveys in Aotearoa/New Zealand. International Journal for Equity in Health, 17, 1-15. https://doi.org/10.1186/s12939-018-0735-y

Crooks, N., Smith, A., \& Lofton, S. (2021). Building bridges and capacity for Black, Indigenous, and scholars of color in the era of COVID-19 and Black Lives Matter. Nursing Outlook, 69, 892-902. https://doi.org/10.1016/j.outlook.2021.03.022

Delgado, C., Upton, D., Ranse, K., Furness, T., \& Foster, K. (2017). Nurses' resilience and the emotional labour of nursing work: An integrative review of empirical literature. International Journal of Nurses Studies, 70, 71-78. https://doi.org/10.1016/i.ijnurstu.2017.02.008

Dawes, T., Muru-Lanning, M., Lapsley, H., Hopa, N., Dixon, N., Moore, C., Tukiri, C., Jones, N., Muru-Lanning, C., \& Oh, M. (2021). Hongi, Harirū and Hau: Kaumātua in the time of COVID-19. Journal of the Royal Society of New Zealand, 51(S1), S23-S36. https://doi.org/10.1080/03036758.2020.1853182

Evans, M. K. (2020). COVID's color line: Infectious disease, inequity, and racial justice. New England Journal of Medicine, 383, 408-410. https://doi.org/10.1056/NEJMp2019445

Haar, J., Roche, M., Brougham, D. (2019). Indigenous insights into ethical leadership: A study of Māori leaders. Journal of Business Ethics, 160, 621-640. https://doi.org/10.1007/s10551-018-3869-3

Health and Disability System Review. (2020). Health and Disability System Review: Final Report: Pūrongo Whakamutunga. Author. https://doi.org/www.systemreview.health.govt.nz/fin al-report

Hunter, K. (2019). The significant cultural value of our Māori nursing workforce. Nursing Praxis in New Zealand, 35(3), 4-6. https://doi.org/10.36951/NgPxNZ.2019.009

Hunter, K., \& Cook, C. (2020). Cultural and clinical practice realities of Māori nurses in Aotearoa New Zealand: The emotional labour of Indigenous nurses. Nursing
Praxis in Aotearoa New Zealand, 36(3), 7-23. https://doi.org/10.36951/27034542.2020.011

Jenkins, D., Burton, C., \& Holmes, D. (2021). (Re)defining nursing leadership: On the importance of parrhèsia and subversion. Journal of Nursing Management, 1-7. Adv online pub. https://doi.org/10.1111/jonm.13520

Kidd, J., Came, H., Doole, C., \& Rae, N. (2022). A critical analysis of te Tiriti o Waitangi application in primary health organisations in Aotearoa New Zealand: Findings from a nationwide survey. Health and Social Care in the Community, 30, e105-e112. https://doi.org/10.1111/hsc.13417

Kidd, J., Came, H., Herbert, S., \& McCreanor, T. (2020). Māori and Tauiwi nurses' perspectives of anti-racism praxis: Findings from a qualitative pilot study. AlterNative, 16, 387-394. https://doi.org/10.1177/1177180120974673

McMeeking, S., Leahy, H., \& Savage, C. (2020). An Indigenous self-determination social movement response to COVID-19. AlterNative, 16, 395-398. https://doi.org/10.1177/1177180120967730

Ministry of Health. (2020a). Background and overview of approaches to COVID-19 pandemic control in Aotearoa/New Zealand. Author. https://www.health.govt.nz/system/files/documents /publications/background-overview-approachescovid-19-pandemic-contro-aotearoa-new-zealand30mar20.pdf

Ministry of Health. (2020b). Initial COVID-19 Māori Response Action Plan. Author.

https://www.health.govt.nz/publication/initial-covid19-Māori-response-action-plan

Ministry of Health. (2021). Northland DHB. Author. https://www.health.govt.nz/new-zealand-healthsystem/my-dhb/northland-dhb

Ruru, S., Roche, M., \& Waitoki, W. (2017). Māori women's perspective of leadership \& wellbeing. Journal of Indigenous Wellbeing, 2, 5-14.

Steyn, N., Binny, R. N., Hannah, K., Hendy, S. C., James, A., Lustig, A., Ridings, K., Plank, M. J., \& Sporle, A. (2021). Māori and Pacific people in New Zealand have a higher risk of hospitalisation for COVID-19. New Zealand Medical Journal, 134(1538), 28-43.

Wilson, D., Moloney, E., Parr, J. M., Aspinall, C., \& Slark, J. (2021). Creating an Indigenous Māori-centred model of relational health: A literature review of Māori models of health. Journal of Clinical Nursing, 30, 35393555. https://doi.org/10.1111/jocn.15859

Wilson, N., Barnard, L., \& Summers, J., Shanks, G. D., Baker, M. (2012). Differential mortality rates by ethnicity in 3 influenza pandemics over a century, New Zealand. Emerging Infectious Diseases, 18, 71-77. https://doi.org/10.3201/eid1801.110035

Ware, F., Breheny, M., \& Forster, M. (2018). Kaupapa Kōrero: A Māori cultural approach to narrative inquiry. AlterNative, 14, 45-53. https://doi.org/10.1177/1177180117744810

Funding: None

Conflict of interest: None 